\title{
Presencia de Receptores de Estrógeno, Progesterona y CBG en el Tracto Genital de Ovejas y Perras. Estudio Inmmunocitoquímico Comparativo
}

\author{
Presence of Estrogen and Progesterone Receptors and CBG in the Female Tract \\ of Sheep and Dogs. Comparative Immunochemistry Study
}

Vasconcellos, C. A.; Sepúlveda, B. N. \& Pacheco, C. C.

VASCONCElloS, C. A.; SEPÚlVEDA, B. N. \& PACHECO, C. C. Presencia de receptores de estrógeno, progesterona y CBG en el tracto genital de ovejas y perras. Estudio inmunocitoquímico comparativo. Int. J. Morphol., 24(3):457-461, 2006.

RESUMEN: Los receptores esteroidales sexuales del tracto genital de la hembra tienen importancia ya que a través de ellos actúan las hormonas responsables de su desarrollo y de sus cambios morfofuncionales. Dado que en su mecanismo de control uno de los factores a tenerse en cuenta son las posibles diferencias entre las distintas especies, los objetivos de nuestro estudio fueron comparar en dos especies distintas la ovina $(\mathrm{O})(\mathrm{n}=6)$ y la canina $(\mathrm{P})(\mathrm{n}=6)$ la presencia de receptores de estrógenos $(\mathrm{RE})$, progesterona $(\mathrm{RP})$ y de CBG en ovario, tuba uterina y útero de hembras prepúberes $(O: n=3 ; P: n=\cdot 3)$ y adultas $(O: n=3 ; P: n=3)$. Se realizaron tinción con $H-E$ e inmunocitoquimica según técnica de Stenberger. Los resultados revelaron: en ambas especies en animales durante el ciclo estral inmunorreactividad (IR) positiva marcada para estrógenos en útero, oviducto y ovario siendo comparativamente los RE más numerosos en oviducto de perra que en oveja. En ambos animales en anestro, la IR para RE fue negativa o leve en útero, no evidenciándose su presencia en otros órganos. Los RP variaron según el estadio del ciclo, no mostrando diferencias destacables entre las especies. En las hembras prepúberes de oveja fueron detectados RE Y RP, mientras que en perras éstos no fueron evidenciados. La CBG mostró IR positiva en el tracto de ambos animales durante el ciclo y fue negativa en prepúberes para ambas especies. Se concluye que existen diferencias, especialmente en hembras prepúberes, donde la presencia de RE y RP es detectable en ovejas no así en perras, siendo además, la presencia de RE comparativamente más marcada en tuba uterina de perra en ciclo que en oveja en el mismo estadio.

PALABRAS CLAVE: Oveja; Perro; Receptores de estrógenos; Receptores de progesterona; CBG.

\section{INTRODUCCIÓN}

Las hormonas esteroidales son esenciales en la reproducción de los mamíferos. Las grandes diferencias entre los géneros son, principalmente, el resultado de los efectos de la testosterona en machos y de los estrógenos y progesterona en hembras.

Los estrógenos y la progesterona se unen a sus receptores específicos para desencadenar una respuesta biológica. Es indiscutible la importancia de éstos durante el período reproductivo de la hembra, ya que interviene en los cambios cíclicos que se producen en el tracto genital durante el ciclo estral (Spencer \& Bazer, 1995; Kimmins \& Mac Laren 2001; Robinson et al., 2001 ). Ellos presentan un complejo mecanismo de control, en el cual uno de los factores que es necesario considerar es la diferencia entre las diversas especies.
Garfolo \& Tasende, (1996 ) y Meikle et al. (1997) observaron la presencia de receptores de estrógenos y progesterona en el endometrio de ovejas prepúberes. En estudios del endometrio de la perra, los receptores de progesterona fueron, en este estadio del desarrollo, muy bajos o indetectables (Lessey et al., 1981).

Según Slayden et al. (1993), en primates y roedores la expresión de los receptores en el endometrio y tubas uterinas es dependiente esencialmente de las hormonas.

Para que se produzca el efecto de las hormonas sobre el receptor, éstas van previamente unidas a un transportador, generalmente una globulina. Entre ellas se encuentra la CBG (corticosteroid-binding globulin), que une tanto progesterona como corticoide. La CBG es una molécula 
que ha sido reconocida en el tracto genital del Hombre y de algunas otras especies (Miska, 1994; Misao, 1994; Vasconcellos et al., 2006) y está involucrada en mecanismos que llevan a la fecundación en humanos y, por lo tanto, se supone que también debería tener participación en los fenómenos reproductivos de otras especies.

El objetivo de nuestro estudio fue comparar en dos especies distintas, la ovina y la canina, mediante estudio inmunocitoquímico, la presencia de receptores de estrógenos (RE), progesterona (RP)y la presencia de CBG en ovario, tuba uterina y útero de hembras prepúberes y adultas.

\section{MATERIAL Y MÉTODO}

Se realizó el estudio en 6 ovejas Rommey Marsh sacrificadas y 6 especímenes de hembras caninas procedentes de ovariohisterectomías por esterilización realizadas en el Hospital de Pequeños Animales de la Universidad Católica de Temuco, Chile (su etapa reproductiva fue confirmada por anamnesis y citología vaginal). Inmediatamente después de obtenidos los órganos se tomaron muestras de pared uterina, tubas uterinas y ovarios de ovejas y perras durante ciclo estral $(O: n=2$ y $P: n=2)$, en anestro $(O: n=1$ y $P: n=1)$ y prepúberes $(\mathrm{O}: \mathrm{n}=3$ y $\mathrm{P}: \mathrm{n}=3$ ) las muestras fueron divididas en dos, una parte fue fijada en Bouin acuoso, para tinciones convencionales y la otra en Methacarn (Carnoy modificado), para inmunocitoquímica (ICQ).

Las inclusiones se hicieron en paraplast, de las cuales se obtuvieron cortes seriados de 5-7 micras. Los análisis morfológicos se hicieron con Hematoxilina y Eosina.

Para ICQ, las muestras fueron procesadas como describe Sternberger (1979) con el método del PAP, según técnica del segundo anticuerpo.

En la serie para los receptores estrogénicos alfa se utilizaron como $1^{\text {er }}$ anticuerpo (Ac) o específico, un monoclonal (Dako, M7047), como $2^{\circ} \mathrm{Ac}$ : (-) IgG ratón obtenido en conejo (Dako, Z0109) y el PAP fue PAPratón (Dako, P0850). En la serie para los receptores de progesterona, se utilizaron como $1^{\mathrm{er}} \mathrm{Ac}$, un policlonal (Dako, A0098), como $2^{\circ} \mathrm{Ac}$ : (-) IgG conejo obtenido en: cerdo (Dako, Z0196) y PAP fue PAP-conejo (Dako, Z0113). El revelado se hizo con 3,3'-diaminobenzidina (Dako, S-3000 ó Sigma) y $\mathrm{H}_{2} \mathrm{O}_{2}$ por 1-5 min., para luego ser deshidratados y montados en Entellan (Merck). Para CBG, el anticuerpo específico fue un policlonal (-)h CBG, obtenido en conejo (Biogénesis Inc, USA; y de propia producción); el $2^{\circ}$ Ac: Dako, Z0109 y PAP conejo: Dako, Z0113. El revelado se hizo con 3,3'diaminobenzidina (Dako, S-3000 ó Sigma) y $\mathrm{H}_{2} \mathrm{O}_{2}$ por 1-5 min., para luego ser deshidratados y montados en Entellan (Merck). Una vez finalizada la reacción, los preparados fueron teñidos con hematoxilina, por 1030 segundos, como tinción de contraste.

Según la intensidad de la tinción se uso la clasificación de positividad fuerte o marcada $(+++)$, moderada (++), débil o leve (+) y negativa (-) (4 ). La intensidad de reacción de las muestras fue comparadas con controles negativos.

El estudio morfológico (con HE y la ICQ) y las fotografías se realizaron con un microscopio Carl Zeiss, Axiolab,c/cámara MC80 DX.

\section{RESULTADOS}

Los resultados fueron: receptores de estrógenos (RE) en oveja durante el ciclo estral, inmunorreactividad positiva moderada en el estroma y el epitelio glandular endometrial y en epitelio superficial y estroma de la tuba uterina (Fig. 1 A). En perra la inmunorreactividad en endometrio fue similar, pero en tuba uterina la positividad fue más marcada (Fig 1 B). Los RE mostraron inmunorreactividad leve o negativa en ovejas y perras anéstricas.

Los receptores de progesterona (RP) tanto en oveja como en perra, mostraron, en los 3 órganos, inmunopositividad leve en animales cíclicas e inmunorreactividad leve o negativa en animales acíclicos.

Receptores de estrógenos (RE) en oveja prepúber mostraron positividad moderada (Fig. 2 A) y receptores de progesterona positividad leve a moderada en oveja prepúber. (Fig 2 B). En perra, ambos receptores fueron negativos en el mismo estadio.

La inmunorreactividad para CBG en endometrio y en tuba uterina, fue marcada en ovejas y perras en ciclo estral y negativa en prepúberes y anéstricas. En ovario, se observó en ovejas y perras durante el ciclo, reacción inmunopositiva a la CBG en células foliculares, en el fluido folicular y en células estromales diseminadas en forma grupal o aislada, es llamativa su presencia asociada con vasos sanguíneos. 


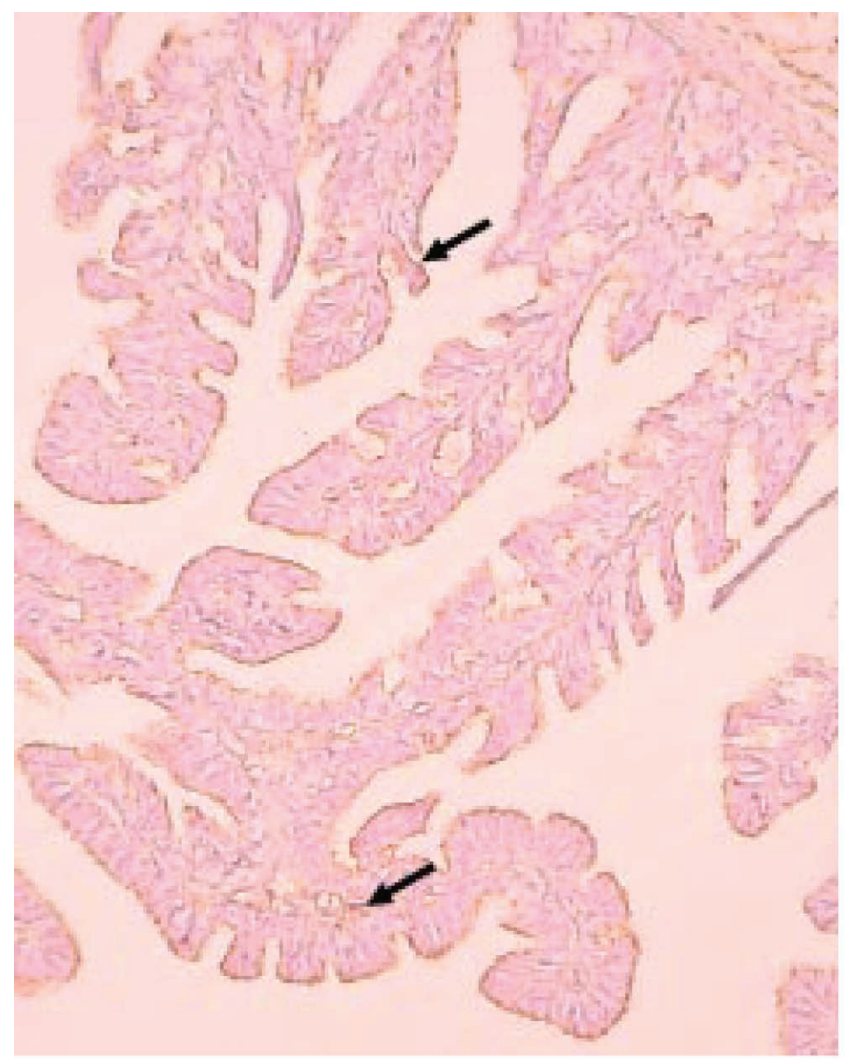

Fig. 1A. Receptores de estrógenos con inmunopositividad moderada en células del epitelio tubario y estroma en oveja. Nótese la inmunoreactividad (flechas) que indica la presencia de receptores (400 X).

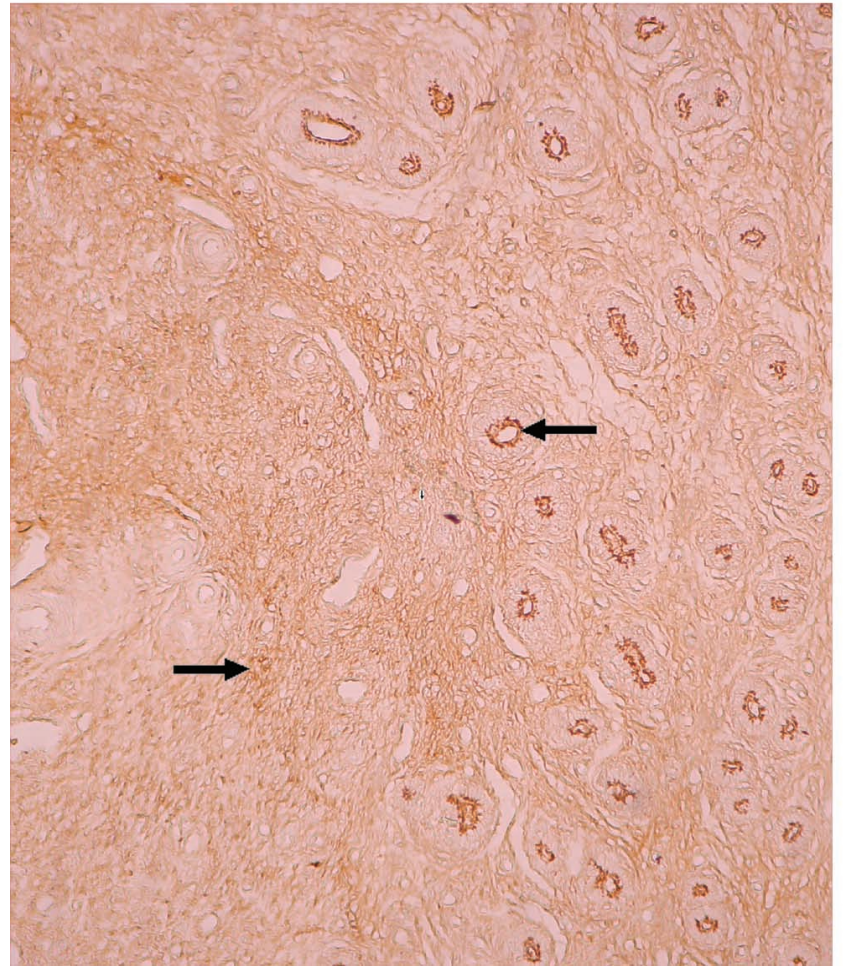

Fig. 2A. Localización inmunocitoquímica de receptores de estrógenos en células del epitelio glandular y estroma endometrial en oveja. Nótese la inmunoreactividad (flechas) que indica la presencia de receptores. ICQ. (400 X).
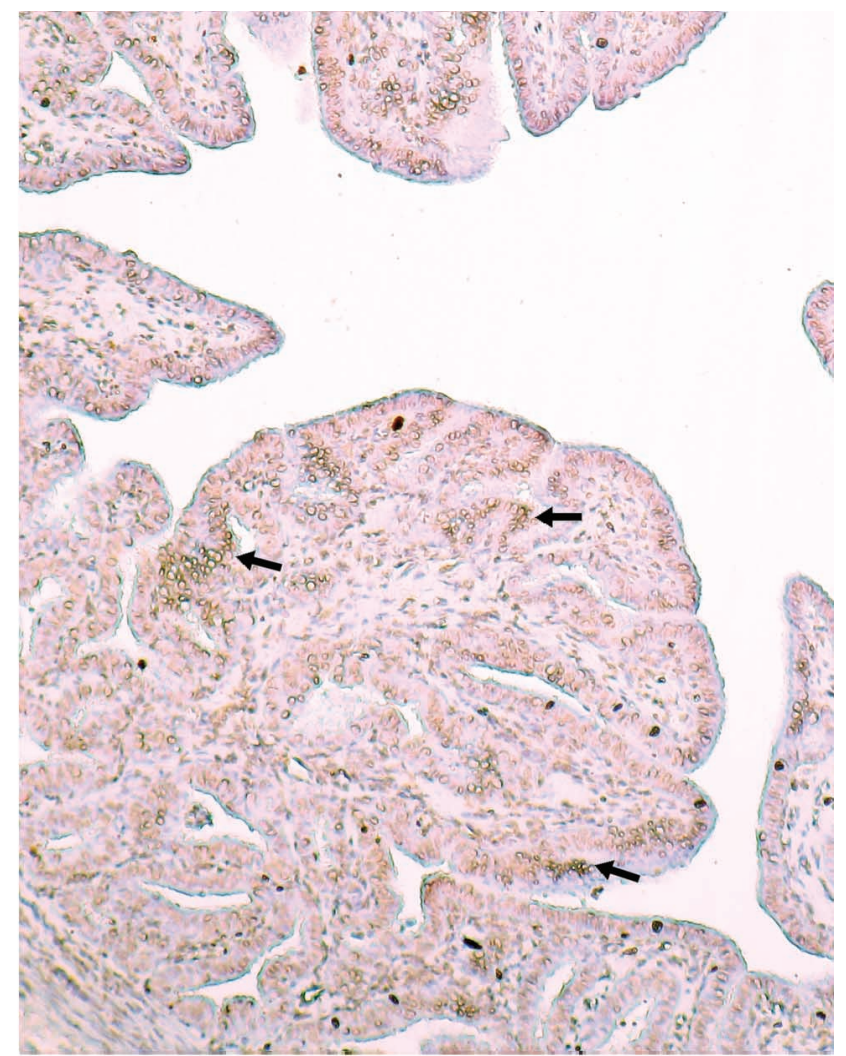

Fig. 1B. Receptores de estrógenos con inmunopositividad marcada en células del epitelio tubariol y estroma en perra. Nótese la inmunoreactividad (flechas) que indica la presencia de receptores $(400 \mathrm{X})$.

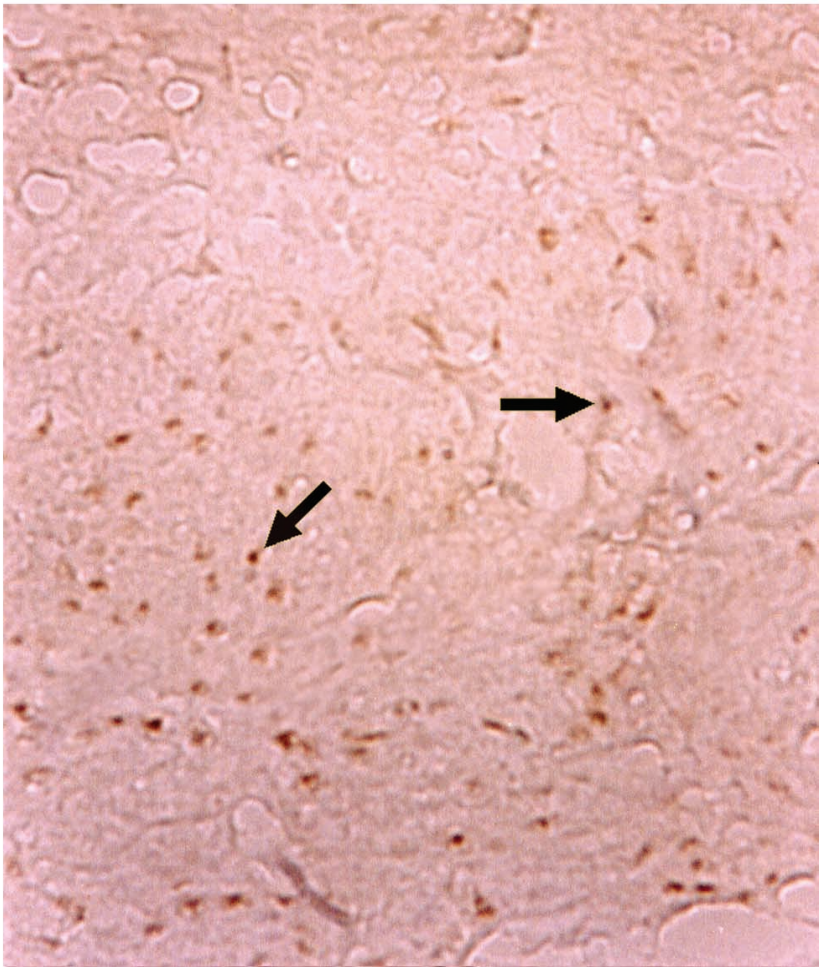

Fig. 2B. Localización inmunocitoquímica de receptores de progesterona en células estromales en oveja. Nótese la inmunoreactividad (flechas) que indica la presencia de receptores. ICQ. ( $400 \mathrm{X})$. 


\section{DISCUSIÓN}

Los receptores esteroidales sexuales tienen primordial importancia en los mecanismos reproductivos. El tracto genital es muy sensible a la acción de las hormonas sexuales las que responden por medio de sus receptores específicos modificando sus características estructurales (Spencer \& Bazer; Kimmins \& Mac Laren y Robinson). La respuesta celular depende de distintos factores que afectan la sensibilidad y función de los tejidos, como son el número y afinidad a sus receptores (tipos y subtipos de ellos), el estado hormonal, la expresión selectiva en los órganos diana, la etapa de desarrollo y el estadio reproductivo en que se encuentre el animal y la diferencia entre las diversas especies (Meikle et al., 2004).

La presencia de RE y RP ha sido estudiada en el tracto genital de distintas especies. En las ovejas se estudió su presencia en el útero y tubas uterinas de animales prepúberes y en ciclo (Garfolo \& Tasende; Meikle et al., 1997, 2000, 2001, 2004 y Vasconcellos et al., 2006 ). Meikle, et al. (2004), consideran que los esteroides gonadales regulan a sus receptores de estrógeno y progesterona de forma diferente a lo largo del tracto genital de la oveja, sugiriendo que las células diana de los tejidos pueden modular distintas respuestas a los mismos niveles sanguíneos circulantes de hormona.

En perras, según Lessey et al., los receptores de progesterona fueron en este estadio del desarrollo, bajos o indetectables en el útero.

Vermeirsch et al. (1998, 1999, 2000), estudiaron la presencia de receptores de estrogeno y progesterona en útero y tubas uterinas de perra y observaron que su fluctuación fue más pronunciada en el estroma endometrial que en el epitelio glandular, concluyendo que el papel de la células estromales en la regulación de los cambios ciclicos endometriales normales como patológicos no debe ser subestimado, ya que ellas podrían mediar la acción de varias hormonas esteroidales sobre el epitelio.
En primates y roedores la expresión de los receptores en las tubas uterinas es dependiente de las hormonas (Slayden et al.) y su regulación sería en éstas, similar a la del útero: aumentaría con los estrógenos y disminuiría con la progesterona.

Los resultados de nuestro estudio mostraron en ambas especies, presencia RE en útero y tubas uterinas durante el ciclo estral siendo la reactividad en la células estromales más marcada que en epitelio. En ovario también se detectaron receptores estrogénicos, principalmente en las células foliculares. Los RP fueron leves o negativos.

La presencia de RE y RP en endometrio de ovejas prepúberes fue siempre detectable con reactividad epitelial y principalmente estromal, no así en el endometrio de perras en igual estadio, en que no fueron detectables.

Un hecho llamativo fue la presencia de receptores de estrógeno comparativamente en mayor cantidad en estroma y epitelio de tuba uterina de perra en ciclo que en oveja en el mismo estadio.

La CBG fue demostrable en ambas especies durante el ciclo siendo negativa en prepúberes en los dos animales. Su presencia sugiere su posible participación en los fenómenos reproductivos de estas especies.

Concluimos que las diferencias encontradas podrían indicar que no todas las especies mamíferas expresan sus receptores a hormonas esteroidales en una misma etapa o con la misma intensidad, en un período determinado de su vida reproductiva. Existirían ciertas especies que, ya al nacer, presentan dichos receptores desarrollados y/o que poseen una cantidad evidenciable a la inmunocitoquímica, y otras especies que sólo los expresan más tardíamente, en la pubertad, o cuando ya existe actividad cíclica hormonal con niveles hormonales más elevados.

VASCONCELlOS, C. A.; SEPÚLVEDA, B. N. \& PACHECO, C. C. Presence of estrogen and progesterone receptors and CBG in the female tract of sheep and dog. Comparative immunochemistry study. Int. J. Morphol., 24(3):457-461, 2006.

SUMMARY: The sexual steroid receptors of the genital tract of the female has importance since on them the hormones responsible for their development and morphofuncional changes act. Due that in their control mechanism one of the factors to be kept in mind is the possible differences among the diverse species. The objective of our study was to compare in two different species sheep $(O)(n=6)$ and canine $(P)(n=6)$ the presence of receptors of estrogens (RE), progesterone (RP) and the presence of $\mathrm{CBG}$ in ovary, oviduct and uterus of female prepúberes $(\mathrm{O}: \mathrm{n}=3 ; \mathrm{Pn}=\cdot 3)$ and mature: $(\mathrm{O}: \mathrm{n}=3 ; \mathrm{Pn}=\cdot 3)$ We use H-E tint and and inmunocito chemistry according to technique of Stenberger. The results revealed: in both species of animals during the estral cycle: Inmunorreactivity (RI) positive marked for estrogens in uterus, oviduct and ovary being comparatively much more numerous RE in dog oviduct that in sheep. In both animals in anestro RE was negative or light in uterus, without evidenced of their presence in other organs. The RP varied according to the stage of the cycle not showing remarkables differences among the species. In the prepuber female sheep RE and RP were detected while in dogs they were not evidenced. The CBG showed positivity in the tract of both animals during the cycle and it was negative in both prepuber species We concludes that differences exist especially in prepuber female where the presence of RE and RP are detectable in sheep and no detectable in dogs, being further the comparatively presence of RE in dog oviduct in cycle more marked that in sheep in the same stage..

KEY WORDS: Sheep; Dog; Estrogens receptors; Progesterone receptors; CBG. 


\section{REFERENCIAS BIBLIOGRÁFICAS}

Garfolo, E.G. \& Tasende, C. Uterine estrogen and progesterone receptors in prepuberal ewe distribution in myometrium, endometrium, and caruncles. Vet. Res. 27:177-3, 1996.

Kimmins, S. \& Mac Laren, L. A. Oestrous cycly and pregnancy effects on the distributionoestrogen and progesterone receptors in bovine endometrium. Placenta 22:742-8, 2001.

Lessey, B. A.; Wahawisan, R. \& Gorell,T.A. Hormone regulation of cytoplasmic estrogen and progesterone receptors in the beagle uterus and oviduct. Moll. Cell. Endocrinol., 21(2):171-80, 1981.

Meikle, A.; Tasende, C.; Rodríguez, M. \& Garófalo, E. G. Effects of estradiol and progesterone on the reproductive trac and on uterine sex steroid receptors in female lambs. Theriogenology, 48:1105-13.1997.

Meikle, A.; Forsberg, M.; Shalin, L.; Masironi, B.; Tasende, C.; Rodríguez-Piñon, M. \& Garófalo, E. G. A biphasic action of estradiol on estrogen and progesterone receptor expression in the lamb uterus. Reprod. Nutr. Dev. 40: 283-93.2000.

Meikle, A.; Garófalo, E. G.; Rodríguez-Piñon, M.; Tasende, C. \& Sahlin, L. Regulation by gonadal steroids of estrogen and progesterone receptors along the reproductive trac in lambs. Acta Vet. Scand., 42:1319, 2001

Meikle, A.; Tasende, C.; Sosa, C. \& Garófalo, E. G. The rol of sex steroid receptors in sheep female reproductive physiology. Reprod. Nutr. Dev., 16:385-94, 2004.

Misao, R.; Hori, M.; Ichigo, S.; Fujimoto, J.; Tamaya, T. Corticosteroid-bindingglobulin mRNA levels in human uterine endometrium. Steroids, 59:603-7, 1994.

Miska, W.; Fehl, P.; HenkeL, R. Biochemical and immunological characterzation of the acrosome reaction-inducing substance (ARIS) of hFF. Biochem. Biophys. Res. Commun., 199(1):125-9, 1994.

Robinson, R. S.; Mann, G. E.; Lamming, G. E. \& Wathes, D. C. Expression of oxytocin, oestrogen and progesterone receptors in uterine biopsy samples through the oestrus cycle and early pregnancy in cows. Reproducction, 122: 965-79, 2001.

Slayden, O. D.; Hirst, J. J. \& Brenner, R. M. Estrogen action in the reproductive tract rheus monkeysduring during antiprogestin treatment. Endocrinology, 132:1845-56, 1993.
Spencer, T. E. \& Bazer, F. W. Temporal and spatial alterations in uterine estrogen receptor and progesterone receptor gene expression during the estrous cycle and early pregnancy in the ewe. Biol. Reprod., 53:1527$43,1995$.

Sternberger, L. A. The unlabled antibody (PAP) method,introduction. J. Histochem. Cytochem., 27(12):1657-65, 1979.

Vasconcellos, A.; Peña, P. \& Sepúlveda, N. Estudio histo morfológico comparativo del endometrio de la oveja prepúber y en anestro bajo influencia hormonal cíclica”. Rev. Cient. FCV-LUZ., 15(4):334-7, 2005.

Vasconcellos, A.; Peña, P.; Sepúlveda, N.; Astudillo, M. y Cabezas, P. P. Presencia de CBG y receptores de Estrógeno, fracción alfa, y Progesterona en el sistema reproductor de ovejas en distintos estadios del ciclo reproductivo.- Estudio inmunocitoquímico. IV Reunión Anual Sociedad de Andrología y Gametología de Chile. VI Jornadas Internacionales de Medicina Reproductiva y Biología de la Reproducción. Temuco, Chile. Enero 2005. Int. J. Morphol., 24(Suppl. 1):125, 2006.

Vermeirsch, H, Simoens, P. Variation in the estrogen receptor content of canine uterine tissue throughout the estrous cycle. Ital. J. Anat. Embryol., 103 (4 Suppl. 1):267-75, 1998.

Vermeirsch, H.; Simoens, P.; Hellemans, A.; Coryn, M. \& Lauwers, H. Immunohistochemical detection of progesterone receptors in the canine uterus and their relation to sex steroid hormone levels. Theriogenology, 53(3):773-88, 2000.

Vermeirsch, H.; Simoens, P.; Lauwers, H. \& Coryn, M. Immunohistochemical detection of estrogen receptors in the canine uterus and their relation to sex steroid hormone levels. Theriogenology, 51(4):729-43, 1999.

Dirección para correspondencia:

Prof. Dra. Adriana Vasconcellos Costa

Facultad de Medicina

Universidad de La Frontera

Casilla 54-D

Temuco - CHILE

Email:avascon@ufro.cl

Recibido : 12-01-2006

Aceptado: 18-06-2006 
